Microgravity Flame Spread in Exploration Atmospheres: Pressure, Oxygen, and Velocity Effects on Opposed and Concurrent Flame Spread

Sandra L. Olson and Gary A. Ruff

Glenn Research Center, Cleveland, Ohio

Fletcher J. Miller

San Diego State University, San Diego, California 


\section{NASA STI Program . . . in Profile}

Since its founding, NASA has been dedicated to the advancement of aeronautics and space science. The NASA Scientific and Technical Information (STI) program plays a key part in helping NASA maintain this important role.

The NASA STI Program operates under the auspices of the Agency Chief Information Officer. It collects, organizes, provides for archiving, and disseminates NASA's STI. The NASA STI program provides access to the NASA Aeronautics and Space Database and its public interface, the NASA Technical Reports Server, thus providing one of the largest collections of aeronautical and space science STI in the world. Results are published in both non-NASA channels and by NASA in the NASA STI Report Series, which includes the following report types:

- TECHNICAL PUBLICATION. Reports of completed research or a major significant phase of research that present the results of NASA programs and include extensive data or theoretical analysis. Includes compilations of significant scientific and technical data and information deemed to be of continuing reference value. NASA counterpart of peer-reviewed formal professional papers but has less stringent limitations on manuscript length and extent of graphic presentations.

- TECHNICAL MEMORANDUM. Scientific and technical findings that are preliminary or of specialized interest, e.g., quick release reports, working papers, and bibliographies that contain minimal annotation. Does not contain extensive analysis.

- CONTRACTOR REPORT. Scientific and technical findings by NASA-sponsored contractors and grantees.

- CONFERENCE PUBLICATION. Collected papers from scientific and technical conferences, symposia, seminars, or other meetings sponsored or cosponsored by NASA.

- SPECIAL PUBLICATION. Scientific, technical, or historical information from NASA programs, projects, and missions, often concerned with subjects having substantial public interest.

- TECHNICAL TRANSLATION. Englishlanguage translations of foreign scientific and technical material pertinent to NASA's mission.

Specialized services also include creating custom thesauri, building customized databases, organizing and publishing research results.

For more information about the NASA STI program, see the following:

- Access the NASA STI program home page at http://www.sti.nasa.gov

- E-mail your question via the Internet to help@ sti.nasa.gov

- Fax your question to the NASA STI Help Desk at 301-621-0134

- Telephone the NASA STI Help Desk at 301-621-0390

- Write to: NASA Center for AeroSpace Information (CASI) 7115 Standard Drive Hanover, MD 21076-1320 
Microgravity Flame Spread in Exploration Atmospheres: Pressure, Oxygen, and Velocity Effects on Opposed and Concurrent Flame Spread

Sandra L. Olson and Gary A. Ruff

Glenn Research Center, Cleveland, Ohio

Fletcher J. Miller

San Diego State University, San Diego, California

Prepared for the

38th International Conference on Environmental Systems

sponsored by the Society of Automotive Engineers International

San Francisco, California, June 28-July 2, 2008

National Aeronautics and

Space Administration

Glenn Research Center

Cleveland, Ohio 44135 


\section{Acknowledgments}

The research at NASA Glenn's Zero Gravity Research Facility was supported by NASA's Fire Prevention, Detection, and Suppression Program. We thank the personnel of the NASA Glenn Zero Gravity Research

Facility for upgrading the experiment apparatus and conducting the drop testing.

We thank Glenn's Spacecraft Fire Prevention team for reviewing this work.

Trade names and trademarks are used in this report for identification only. Their usage does not constitute an official endorsement, either expressed or implied, by the National Aeronautics and Space Administration.

Level of Review: This material has been technically reviewed by technical management.

Available from

NASA Center for Aerospace Information 7115 Standard Drive

Hanover, MD 21076-1320
National Technical Information Service 5285 Port Royal Road Springfield, VA 22161

Available electronically at http://gltrs.grc.nasa.gov 


\title{
Microgravity Flame Spread in Exploration Atmospheres: Pressure, Oxygen, and Velocity Effects on Opposed and Concurrent Flame Spread
}

\author{
Sandra L. Olson and Gary A. Ruff \\ National Aeronautics and Space Administration \\ Glenn Research Center \\ Cleveland, Ohio 44135 \\ Fletcher J. Miller \\ San Diego State University \\ San Diego, California 92182
}

\begin{abstract}
Microgravity tests of flammability and flame spread were performed in a low-speed flow tunnel to simulate spacecraft ventilation flows. Three thin fuels were tested for flammability (Ultem 1000 (General Electric Company), 10 mil film, Nomex (Dupont) HT90-40, and Mylar G (Dupont) and one fuel for flame spread testing (Kimwipes (Kimberly-Clark Worldwide, Inc.). The $1 \mathrm{~g}$ Upward Limiting Oxygen Index (ULOI) and $1 \mathrm{~g}$ Maximum Oxygen Concentration (MOC) are found to be greater than those in $0 \mathrm{~g}$, by up to $4 \%$ oxygen mole fraction, meaning that the fuels burned in $0 \mathrm{~g}$ at lower oxygen concentrations than they did using the NASA Standard 6001 Test 1 protocol.

Flame spread tests with Kimwipes were used to develop correlations that capture the effects of flow velocity, oxygen concentration, and pressure on flame spread rate. These correlations were used to determine that over virtually the entire range of spacecraft atmospheres and flow conditions, the opposed spread is faster, especially for normoxic atmospheres. The correlations were also compared with $1 \mathrm{~g}$ MOC for various materials as a function of pressure and oxygen. The lines of constant opposed flow agreed best with the $1 \mathrm{~g}$ MOC trends, which indicates that Test 1 limits are essentially dictated by the critical heat flux for ignition. Further evaluation of these and other materials is continuing to better understand the $0 \mathrm{~g}$ flammability of materials and its effect on the oxygen margin of safety.
\end{abstract}

\section{Introduction}

For future space missions, NASA is planning to increase the oxygen concentration and reduce the total pressure of the atmosphere in the Orion crew exploration vehicle, the Altair lander, and future lunar habitats (ref. 1). This atmosphere has the advantages of requiring a lower mass of inert gas $\left(\mathrm{N}_{2}\right)$, lowering vehicle internal pressures, and shortening or eliminating the pre-breathing time required to purge nitrogen from the bloodstream before Extra Vehicular Activity (EVA). However, an enriched oxygen atmosphere also has a significant disadvantage - increased flammability of materials.
One of the major lessons learned from the Apollo 1 fire is that it is impossible to eliminate all ignition sources (ref. 2), so fire prevention is achieved in spacecraft through material control and the use of fire resistant materials. Since Skylab, the Space Shuttle and the International Space Station (ISS) have operated at normal sea-level conditions (air, 21\% oxygen $/ 79 \%$ nitrogen by volume at 14.7 psia total pressure) except for brief pre-EVA activities when oxygen levels are increased for a short period of time to $30 \%$ oxygen while the total pressure is lowered to 10.2 psia. Many of the materials now used in the Shuttle or on ISS are therefore only tested and rated to $30 \%$ oxygen at 10.2 psia.

The Crew Exploration Vehicle (CEV), Orion, and the lunar lander, Altair, are designed to operate from 8.0 to 14.9 psia and at a maximum of 30 and $34 \%$ oxygen concentration respectively. The transition from higher pressure, lower oxygen concentrations to lower pressure, higher oxygen concentrations will occur as exploration needs change from ISS crew exchange to lunar missions. As the oxygen concentration increases, the cabin pressure decreases to follow the normoxic curve which keeps the partial pressure of oxygen constant at the normal atmospheric air equivalent of $0.21 \mathrm{~atm}$, or 3.09 psia. The partial pressure of oxygen in the spacecraft will be controlled to 2.6 to 3.1 psia, which creates a band of operating conditions on the hypoxic side of the normoxic curve.

NASA tests materials for flammability using NASA STD6001 Test 1 (ref. 3), which is an upward burning test at the worst-case atmospheric conditions in which the material will be used. Materials that do not self-extinguish after 6 in. of burning must undergo other special considerations and/or tests if they are to be used on spacecraft. During the early stages of the Constellation Program (CxP), NASA Materials and Processes (M\&P) personnel realized that changes to the baseline oxygen concentration during vehicle development or from vehicle to vehicle during the implementation of the $\mathrm{CxP}$ would require repeated testing of many materials to document their flammability at the new baseline.

Anticipating these changes in the baseline oxygen concentration, NASA set out to determine the maximum oxygen concentration (MOC) for a set of spacecraft materials identified by NASA M\&P personnel. (The MOC was defined as the 
maximum oxygen concentration at which a material passed the standard 1-g flammability test, NASA-STD-6001 Test 1. The measurement of the MOC using the standard Test 1 protocol has been evaluated (refs. 4 to 7 ) to provide additional information about the flammability limits of the material and not just a pass/fail statement regarding its use in the worstcase atmosphere. This approach allows a better understanding of the margin of safety for the material in the real-use atmosphere, but has not been formally approved as a standard test.

In this approach (ref. 5), the oxygen concentration in Test 1 is successively reduced to identify the Upward Limiting Oxygen Index (1g ULOI) and the Maximum Oxygen Concentration (1g MOC) that consistently results in selfextinguishment of the material. The $1 \mathrm{~g}$ ULOI is defined as the oxygen concentration at which a material passes the NASA STD 6001 Test 1 burn length criterion approximately half the time. The $1 \mathrm{~g}$ MOC is defined as the oxygen concentration where at least five samples passed the burning criterion (ref. 3) and where at least one sample failed in the environment that contained 1 percent more oxygen by volume.

The objective of this work is to begin to assess the relative flammability limits between Test 1 and concurrent flammability limits in microgravity, to better understand how the $1 \mathrm{~g}$ margins of fire safety in spacecraft environments are modified in actual microgravity. Based on microgravity tests conducted at various oxygen levels with three fuels tested previously by WSTF (ref. 8), we define an oxygen margin of safety parameter that can be used to assess material safety in the intended use atmosphere. In addition, the effects of oxygen concentration, pressure, and forced flow velocity are studied to understand how changing the atmosphere along the normoxic curve affects the robustness of the flame as measured by flame spread rate.

\section{Experimental Apparatus}

The microgravity tests are performed in a low-speed flow tunnel that provides 0 to $30 \mathrm{~cm} / \mathrm{s}$ forced flow of gas $(0$ to $100 \% \mathrm{O}_{2}$ in diluent) through a $20 \mathrm{~cm}$ ID duct at 0 to $14.7 \mathrm{psia}$ pressure. The flow tunnel is mounted on a NASA Zero Gravity Research Facility drop rig bus (ref. 9), but with modifications to the flow system and software control. The flow system of the rig is shown schematically in figure 1 . The flow modifications include a second gas reservoir such that oxygen concentrations (or another parameter such as diluent or extinguishing agent) can be changed during a test and a new back pressure control valve for greater flow capacity of up to $30 \mathrm{~cm} / \mathrm{s}$ at pressures up to $14.7 \mathrm{psia}$. Higher permeability porous plates and honeycomb were installed to improve the flow distribution and laminarity at these higher flow rates. For the material flammability tests, the switching of the flow between source bottles was timed so that the sample was ignited in an enriched oxygen concentration greater than the $1 \mathrm{~g}$ ULOI, and the test oxygen level reached the sample shortly after release into zero gravity. The established flame then had $\sim 5 \mathrm{sec}$ in which to respond to the new atmosphere by either extinguishing $(0 \mathrm{~g}$ MOC) or shrinking to a reduced burning state at the lower oxygen concentration. The lowest oxygen concentration where the flame survived to the end of the drop is considered the $0 \mathrm{~g}$ ULOI. While some of these flames may extinguish given longer time, the limits provided by the Zero Gravity Research Facility tests are a conservative measure of the limits in $0 \mathrm{~g}$. Note these limits are not identical to the $1 \mathrm{~g}$ limits due to the intrinsic limitations of the drop time, but they are a reasonable comparison.

Tests were performed using a fuel sample taped to a sheet metal sample holder with an igniter wire on either the upstream or downstream end of the $5-\mathrm{cm}$ wide by $10-\mathrm{cm}$ long sample (fig. 2). The flow was started before the drop to establish a steady flow speed and pressure in the tunnel prior to the drop rig release. The hot wire igniter was energized either in $1 \mathrm{~g}$ or at release, depending on the objective of the test (flammability limit tests used $1 \mathrm{~g}$ ignition; flame spread tests used $0 \mathrm{~g}$ ignition). The microgravity period lasted $5.18 \mathrm{sec}-$ the first $2 \mathrm{sec}$ of which are typically used for $0 \mathrm{~g}$ ignition and flame spread away from the igniter. When the drop rig reaches the bottom of the evacuated drop shaft and stops in the deceleration cart, the test section is vented to vacuum to extinguish the flame.

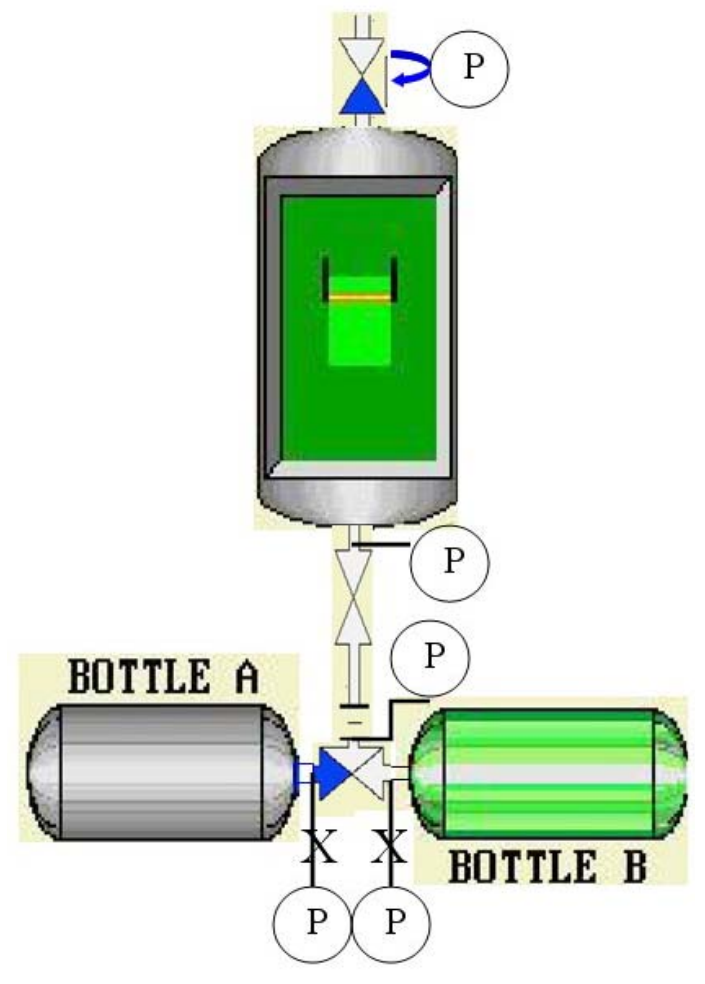

Figure 1.-Schematic of the flow system on the Drop Bus. Two separate bottles can contain two gas mixtures so that conditions (oxygen concentration, diluent, pressure) can be switched during the experiment if needed. A critical flow orifice controls the flow through the test chamber, while a back pressure valve controls the pressure in the chamber. The sample and orange igniter are shown within the chamber. 


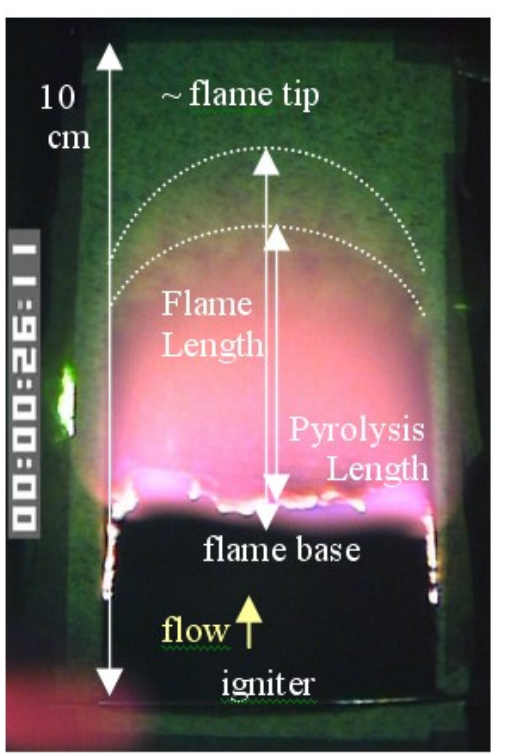

(a)

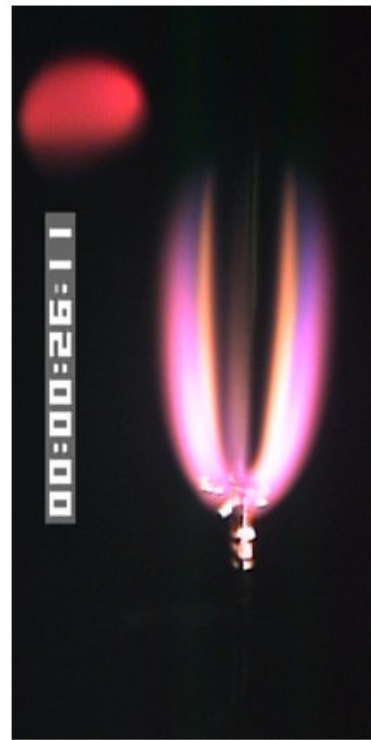

(b)
Figure 2.-(a) Front view of a Kimwipes fuel sample in the $0.5 \mathrm{~mm}$ thick stainless steel holder, showing a concurrent flame test at $24 \%$ oxygen, $30 \mathrm{~cm} / \mathrm{s}, 6.4$ psia (not near limit). The cutout in the holder is 5 - by $10-\mathrm{cm}$ for the sample, but the holder itself is $20-\mathrm{cm}$ wide and over $35-\mathrm{cm}$ long, extending $12.7 \mathrm{~cm}$ upstream of the sample. The Kimwipes sample appears green due to the LED illumination. The igniter can be positioned at either end of the sample, so both opposed or concurrent (shown) tests can be done in the same holder. (b) Side view of same flame. The constant intensity red LEDs in both views was used to judge the actual flame brightness, since the camera was on auto-gain.

The fuels used in this study include Kimwipes, Ultem 1000, Nomex HT90-40, and Mylar G. Kimwipes are tested to expand the database for thin cellulose fuel that chars as it burns but is not treated for fire resistance. Front and side view images of a Kimwipes burn are shown in figure 2. With this fuel we can obtain flame spread and extinction data in the limited microgravity test time. Ultem 1000 (fire retarded polyetherimide (PEI)) in 10 mil thick film is inherently flameretarding, with self-charring characteristics, a very low smoke signature, very low smoke toxicity, and a low heat-release rate. Nomex HT90-40 is a 12 mil thick fire retarded aromatic nylon fabric which does not melt or drip as it burns. When exposed to a heat source, the Nomex fibers swell and seal the spaces between the fibers, stopping air movement through the fabric and thus inhibiting heat transfer through the fabric. Mylar G is a 5 mil thick plastic film made from polyethylene terephthalate. It is not fire-retarded, melts as it burns, and was selected primarily for its non-charring character.

Ignition and flame spread were recorded by two orthogonal color video cameras with automatic gain control; sample images are shown in figure 2. Flame shape, size, and spread rate were measured using Spotlight software (ref. 10). Relative luminosity is compared between video frames using a constant brightness red LED in the corner of the images which also flashes at release marking the drop in the video.
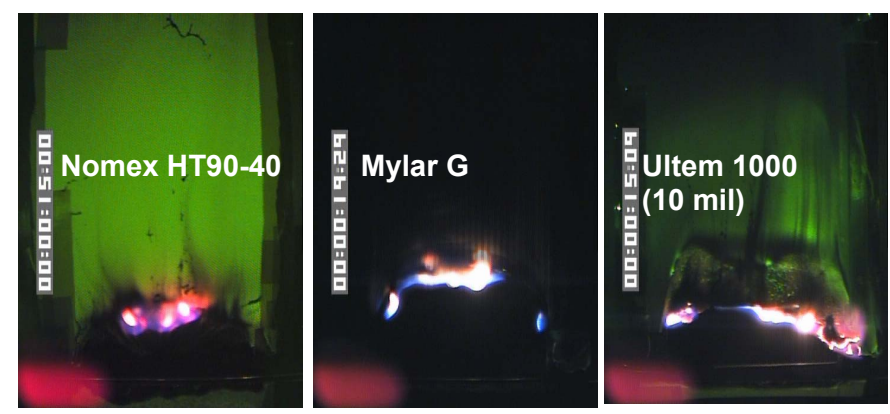

Figure 3.-Front view pictures of microgravity flames on three different fuels samples at the ULOI. The concurrent forced flow velocity was $30 \mathrm{~cm} / \mathrm{s}$. The red LED in lower left is the same true brightness, giving an indication of the relative brightness between the flames. The green LED was not used for the Mylar as it caused too much specular reflection.

\section{Material Flammability Results}

Materials flammability tests were conducted for three materials and the $1 \mathrm{~g}$ ULOI and $1 \mathrm{~g}$ MOC were compared with $0 \mathrm{~g}$ values obtained at a concurrent flow of $30 \mathrm{~cm} / \mathrm{s}$, which is a reasonable maximum local spacecraft ventilation velocity (ref. 11). The limiting oxygen values for each fuel are found in table 1 , and flame images for near limit $0 \mathrm{~g}$ flames are shown in figure 3. The near-limit flames are generally small and localized to the upstream edge of the material. We noticed that any distortion of the burned edge of the material, such as curling, swelling, or contracting, weakens the flame apparently by influencing the flow around the burned edge. Since oxygen transport is critical to microgravity flames, anything that reduces the free flow of oxygen past the sample will reduce the material's flammability.

TABLE 1.-COMPARISON OF 1G AND 0G FLAMMABILITY LIMITS FOR THREE FUELS

\begin{tabular}{|c|c|c|c|c|}
\hline Fuel & $\begin{array}{c}1 \mathrm{~g} \\
\text { ULOI }\end{array}$ & $\begin{array}{c}1 \mathrm{~g} \\
\mathrm{MOC}\end{array}$ & $\begin{array}{c}0 \mathrm{~g} \\
\text { ULOI } \\
\text { (burns) } \\
\end{array}$ & $\begin{array}{c}\mathrm{g} \\
\text { MOC } \\
\text { (extinguishes) } \\
\end{array}$ \\
\hline $\begin{array}{l}\text { Nomex HT90-40 } \\
\text { fabric }\end{array}$ & $\begin{array}{c}25.4 \% \mathrm{O}_{2} \\
( \pm 0.6), \\
14.7 \mathrm{psia}^{*}\end{array}$ & $\begin{array}{c}22 \% \mathrm{O}_{2}, \\
14.7 \text { psia* }\end{array}$ & $\begin{array}{c}23 \% \mathrm{O}_{2}, \\
14.7 \mathrm{psia}, \\
30 \mathrm{~cm} / \mathrm{s}\end{array}$ & $\begin{array}{c}22 \% \mathrm{O}_{2}, \\
14.7 \mathrm{psia}, \\
30 \mathrm{~cm} / \mathrm{s}\end{array}$ \\
\hline $\begin{array}{l}\text { Ultem } 1000 \\
10 \text { mil }\end{array}$ & $\begin{array}{l}26.5 \% \mathrm{O}_{2}, \\
10.2 \text { psia* }\end{array}$ & $\begin{array}{c}24 \% \mathrm{O}_{2}, \\
10.2 \text { psia* }\end{array}$ & $\begin{array}{c}24 \% \mathrm{O}_{2}, \\
10.2 \mathrm{psia}, \\
30 \mathrm{~cm} / \mathrm{s}\end{array}$ & $\begin{array}{c}23 \% \mathrm{O}_{2}, \\
10.2 \mathrm{psia}, \\
30 \mathrm{~cm} / \mathrm{s}\end{array}$ \\
\hline Mylar G & $\begin{array}{l}20.8 \% \mathrm{O}_{2}, \\
10.2 \text { psia* }\end{array}$ & $\begin{array}{c}20 \% \mathrm{O}_{2} \\
10.2 \text { psia* }\end{array}$ & $\begin{array}{c}17 \% \mathrm{O}_{2}, \\
10.2 \mathrm{psia}, \\
30 \mathrm{~cm} / \mathrm{s}\end{array}$ & $\begin{array}{c}16 \% \mathrm{O}_{2} \\
10.2 \mathrm{psia} \\
30 \mathrm{~cm} / \mathrm{s}\end{array}$ \\
\hline
\end{tabular}

*WSTF data (ref. 8)

An example flammability map is shown in figure 4 for Ultem 1000, where the $1 \mathrm{~g}$ limits are compared to $0 \mathrm{~g}$ test results over a range of flow and oxygen concentrations. The observed minimum in the flammability curve is for concurrent flow at the highest velocities achievable in the drop rig $(30 \mathrm{~cm} / \mathrm{s})$, so the remaining fuels were tested at $30 \mathrm{~cm} / \mathrm{s}$ concurrent flow. 


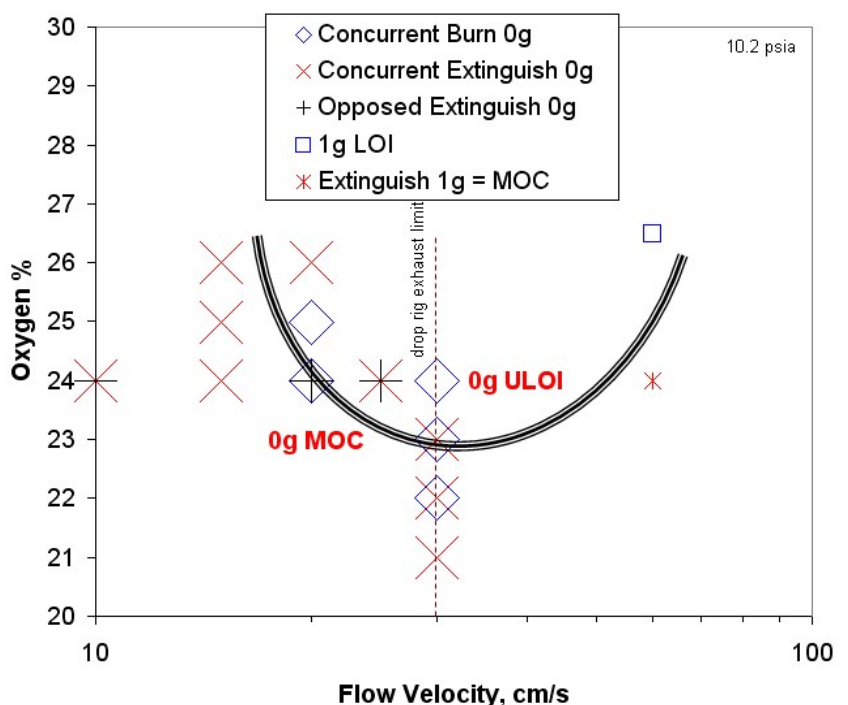

Figure 4.-Ultem 1000, 10 mil film, flammability map as a function of flow and oxygen\%, with the pressure held constant at 10.2 psia. Most of the tests were conducted with concurrent forced flow velocity, but two were with opposed flow. The thick curved line indicates the approximate division between flammable and non-flammable conditions. Near the boundary the same conditions can yield different results due to the randomness of the flames and the samples curling which affects the airflow.

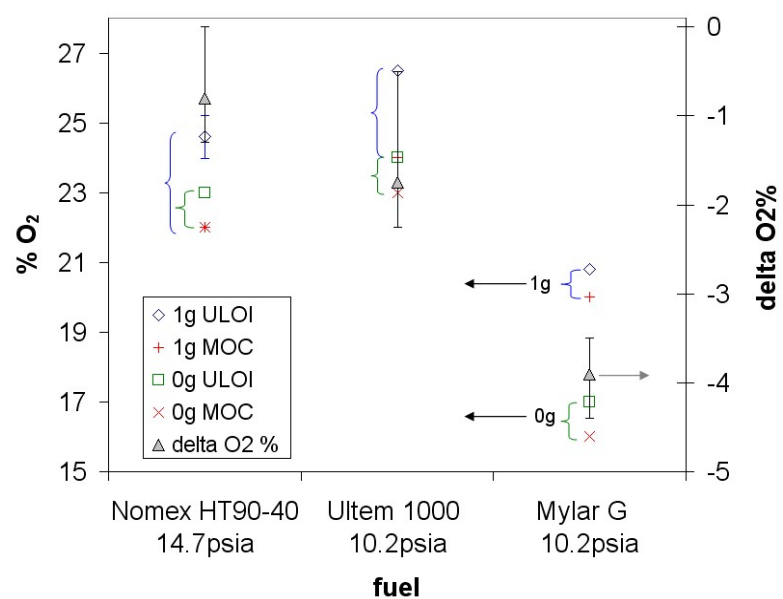

Figure $5 .-1 \mathrm{~g}$ and $0 \mathrm{~g}$ flammability limits for three fuels, and the $\Delta \mathrm{O}_{2} \%$ on the Test 1 margin of safety identified for each fuel, with error bars based on the differences between the ULOI and MOC.

Figure 5 compares the flammability limits from table 1 graphically, and evaluates the oxygen margin of safety for the $1 \mathrm{~g}$ Test 1 data. The $\Delta \mathrm{O}_{2} \%_{0 \mathrm{~g}-\mathrm{g}}$ is defined here as the mean $0 \mathrm{~g}$ limit minus the mean $1 \mathrm{~g}$ limit as follows:

$$
\Delta \mathrm{O}_{2} \%_{0 \mathrm{~g}-\lg }=\left(\frac{(0 \mathrm{~g} U L O+0 \mathrm{~g} M O C}{2}\right)-\left(\frac{(\lg U L O+\lg M O C}{2}\right)
$$

In this equation, the lowest percent $\mathrm{O}_{2}$ at which the material burned in $0 \mathrm{~g}$ for the full test was taken as the $0 \mathrm{~g}$ ULOI; the maximum percent $\mathrm{O}_{2}$ where the material extinguished during the test was taken as the $0 \mathrm{~g}$ MOC. A positive $\Delta \mathrm{O}_{2} \%_{0 \mathrm{~g}-1 \mathrm{~g}}$ means that the flame will propagate in $1 \mathrm{~g}$ at lower oxygen concentrations than in $0 \mathrm{~g}$. Conversely, a negative $\Delta \mathrm{O}_{2} \%_{0 \mathrm{~g}-1 \mathrm{~g}}$ means that the flame will propagate in $0 \mathrm{~g}$ at a lower oxygen concentration than in $1 \mathrm{~g}$ and would result in a reduced margin of safety.

For example, Ultem film is used aboard the Space Shuttle and the International Space Station, both of which have a nominal atmosphere of $21 \%$ oxygen $\pm 2 \%$ oxygen. In $1 \mathrm{~g}$, the mean flammability limit for Ultem is $25.25 \%$, which is at least $2.25 \%$ above the nominal range for the atmosphere. However, in $0 \mathrm{~g}$ the mean flammability limit is $22.5 \%$, which falls within the nominal range for the atmosphere, indicating the material could burn if ignited. The $\Delta \mathrm{O}_{2} \%_{0 \mathrm{~g}-1 \mathrm{~g}}=-2.75 \%$ is a significant negative margin of safety that needs to be considered when deciding if a material is safe for use in spacecraft.

As shown in figure 5, the $1 \mathrm{~g}$ flammability limits are generally not conservative for these materials as evidenced by the negative $\Delta \mathrm{O}_{2} \%_{0 \mathrm{~g}-1 \mathrm{~g}}$, by up to $-4 \%$ oxygen. For concurrent (upward) flow conditions, it is reasonable for materials to be flammable at lower oxygen concentration in low-g than in 1-g because in the absence of buoyancy, the heat loss due to convective flow is greatly reduced. As such, the flame doesn't have to release as much heat as in $1 \mathrm{~g}$ to provide the same amount of heat flux to the unburned fuel. Thus, it is not surprising that the $0 \mathrm{~g}$ flammability limits are lower than the $1 \mathrm{~g}$ flammability limits, which is the general trend noted in table 1 . The evaluation of the magnitude of this $\Delta \mathrm{O}_{2} \%_{0 \mathrm{~g}-1 \mathrm{~g}}$ for other materials is continuing for concurrent flammability limits, to be followed by evaluation of the limits for opposed flow.

\section{Flame Spread Results}

The 0g ULOI and 0g MOC measurements discussed in the previous section allow the difference between $1 \mathrm{~g}$ and $0 \mathrm{~g}$ oxygen flammability limits (or thresholds) to be quantified. However, this data does not quantify the difference in flammability at oxygen concentrations above the $0 \mathrm{~g}$ MOC. As previously stated, atmospheres used in exploration vehicles will generally lie along the normoxic curve, i.e., the locus of ambient pressure/oxygen concentration combinations having the same oxygen partial pressure as standard sea level conditions. It would be useful to quantify material flammability along this curve so that trades between oxygen concentration and ambient pressure can be performed.

One way to determine relative flammability along the normoxic curve is to use flame spread as a measure of flammability. In this section, we describe the flame spread tests, develop correlations between forced flow velocity, oxygen concentration, and pressures to collapse the data onto a single curve, and finally extrapolate them to the normoxic condition.

Thirty concurrent and ten opposed flow flame spread tests were conducted with Kimwipes to evaluate the effects of flow, pressure, and oxygen on the robustness of the flame. The flow velocity varied between 0 and $30 \mathrm{~cm} / \mathrm{s}$, the pressure varied between 3.6 and $14.7 \mathrm{psia}$, and the oxygen percentage ranged 
from 24 to $85 \%$. Spread rates were measured from the video for each test condition. Flame tracking was generally done with the edge view either manually or using an appropriate threshold value for the target. A more detailed report of these results can be found in (ref. 12).

Correlations were developed to capture the effect of all three of the variables (flow, pressure, oxygen) on the measured flame spread rate.

For normal gravity, downward (opposed flow) flame spread over thin fuels, previous investigators found the flame spread rate correlated with $\left(\mathrm{O}_{2}\right)^{0.9}(\mathrm{P})^{0.05}$, with oxygen in mole-fraction and pressure in atm. (ref. 13). There was only a sight pressure dependence noted, so the primary influence on spread rate was from the oxygen concentration in this buoyantly controlled situation.

We found that our new data, as well as previous data from both normal and microgravity (refs. 14 to 16), were wellcorrelated by this relationship except near the quench limit where flow effects play a role. The results are shown figure 6 , where new data as well as those from (refs. 14 and 15) are shown. The spread rate increases nearly linearly with oxygen percentage, while the pressure effect is quite weak in this range. This is in contrast with Bhattacharjee et al. (ref. 17), who showed a much stronger dependence on pressure for fourfold thicker fuel in a quiescent environment. Those tests were shown to be near-limit, where heat losses such as radiation become important. Indeed, even the near-limit data from (refs. 14 and 15) show a fall off from the correlation. Thus, the correlation can be viewed as a worst-case (i.e., highest) prediction of spread rate for a given oxygen and pressure condition.

For concurrent spread, there was no such correlation of experimental data in the literature that we could find, perhaps because in normal gravity the flame spread rate is often acceleratory. Ferkul (ref. 18) did correlate his numerical predictions of spread rate as a function of oxygen and forced flow velocity in a polynomial expression, and noted the spread rate increases approximately linearly with either flow velocity or oxygen percentage.

The best fit of the available experimental data was obtained by using the correlation parameter shown in figure 7 , which captures the linear dependencies we observed for flow and oxygen, and a square root variation with pressure. Here, all our data are shown, along with some earlier near-limit data from Grayson (ref. 19) and Pettegrew (ref. 20). The normoxic data ranged from $24 \%$ oxygen at 12.8 psia to $85 \%$ oxygen at $3.6 \mathrm{psia}$, all at $30 \mathrm{~cm} / \mathrm{s}$ flow. The oxygen varies from 24 to $50 \%$ oxygen at $10.2 \mathrm{psia}$ and $30 \mathrm{~cm} / \mathrm{s}$. Velocity varies from 1 to $30 \mathrm{~cm} / \mathrm{s}$ at $34 \%$ oxygen and $10.2 \mathrm{psia}$. Pressure varies from 5 to 14.7 psia at $40 \%$ oxygen and $30 \mathrm{~cm} / \mathrm{s}$. For most of the range, the spread rate depends linearly on the correlation parameter, but at very low near-limit values the data show a fall off from the linear fit, as predicted (ref. 21). A power law fit is shown for comparison in figure 7 .

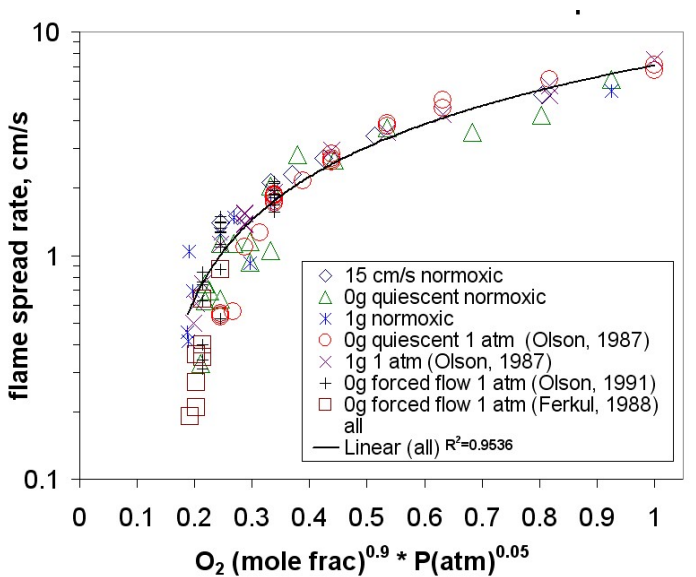

Figure 6.-Flame spread data for Kimwipes, fit to an oxygenpressure correlation based on Magee and McAlevy (ref. 13) for opposed flow under a variety of atmospheric and gravitational conditions. Flow velocity is not captured in this correlation due to the non-monotonic dependence of flame spread at low oxygen concentrations ( $<40 \%)$; below an optimum velocity the flame spread rate increases, and above that it decreases. Above $40 \%$ oxygen, the flame spread rate is independent of forced velocity.

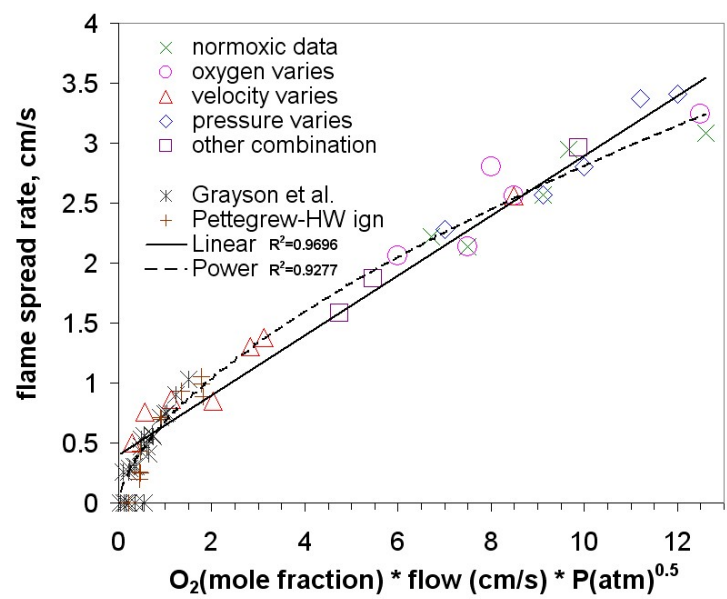

Figure 7.-Concurrent flame spread correlation for Kimwipes combining the effects of forced flow velocity, oxygen concentration, and ambient pressure. The symbols are sized to reflect the estimated error bars based on comparing top and bottom base spread rates. Data from references 18 and 19 are also shown for comparison. A linear fit to all the data is $y=0.2498 x+0.4038$, with $R^{2}=0.97$. A power law fit to the data is $y=0.6763 x^{0.6187}$ with $\mathrm{R}^{2}=0.93$.

Figure 8 applies both flame correlations developed above to determine the boundary where concurrent spread is faster than opposed flame spread. To create this figure, we equate the opposed and concurrent flame spread rates and then solve for the forced flow velocity that makes them equal as a function of oxygen concentration. This was done for two pressures: the normoxic equivalent pressure and $14.7 \mathrm{psia}$. It is seen that over virtually the entire range of spacecraft atmospheres and flow conditions (5 to $20 \mathrm{~cm} / \mathrm{s}$ nominal range (ref. 11) the 


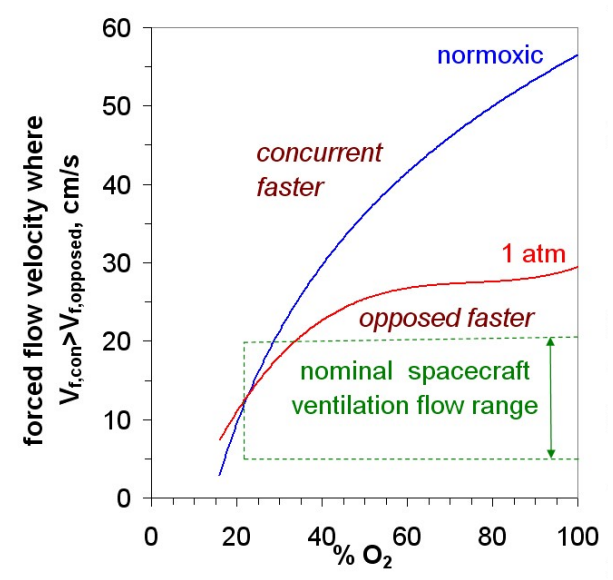

Figure 8.-Oxygen and velocity map showing the region where concurrent flame spread for Kimwipes is faster than opposed flow flame spread in microgravity. The curves were obtained from the linear correlation equations based on the experimental data. The results are shown for two total pressures, the pressure corresponding to normoxic conditions at the particular oxygen mole fraction, and $1 \mathrm{~atm}$. Opposed spread is faster below the lines. Also shown is the nominal space craft ventilation range, demonstrating that in virtually all situations the opposed spread is more rapid.

opposed spread is faster, especially for the normoxic case. However, in the range of 20 to $25 \%$ oxygen, the flame spread rate for opposed and concurrent flow are similar, consistent with the data shown in figure 4 . Furthermore, for the realistic scenario of a sample ignited in a central region rather than at an edge the flame will spread upstream. Any downstream flame would be even further inhibited by the vitiated atmosphere generated by the upstream flame.

The different response of opposed and concurrent flame spread to the normoxic atmosphere is shown in figure 9. For opposed flow, the flame spread increases rapidly with increasing oxygen concentration in the normoxic atmosphere. In contrast, the concurrent flame spread more slowly increases with increasing oxygen concentration as the falling pressure counteracts the increasing oxygen concentration. While this figure shows that the flame spread rate increases as the percent $\mathrm{O}_{2}$ increases along the normoxic curve, the magnitude of the change depends on the direction of the spread. Opposed (or upwind) spread increases from about 1 to $5 \mathrm{~cm} / \mathrm{s}$ as percent $\mathrm{O}_{2}$ goes from 21 to $80 \%$. Concurrent (or downwind) flame spread increases only from about 3 to $4 \mathrm{~cm} / \mathrm{s}$ over this same range of percent $\mathrm{O}_{2}$ for $30 \mathrm{~cm} / \mathrm{s}$ forced flow. The difference between the opposed and concurrent $15 \mathrm{~cm} / \mathrm{s}$ forced flow results is even larger. This trend should be investigated using other types of materials.

Also, recall that the $0 \mathrm{~g} \mathrm{OC}$ data in the previous section were obtained mostly in a concurrent flow configuration. Since the data in figure 9 shows that the flame spread rates between concurrent and opposed flow are significantly different, it is

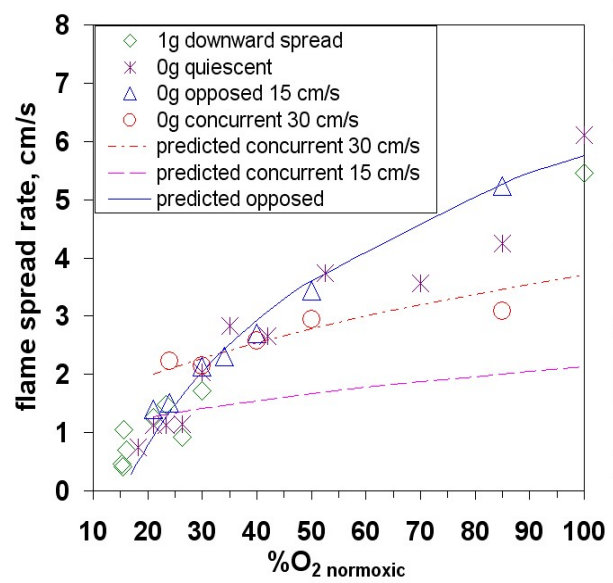

Figure 9.-Opposed and concurrent flame spread for Kimwipes plotted as a function of oxygen concentration in the normoxic atmosphere. The correlations are used for the predictions.

plausible that the flammability limits in $0 \mathrm{~g}$ may also be different, especially for materials whose limits lie at higher oxygen concentrations along the normoxic curve, and should be investigated in future work.

\section{Discussion}

The Test 1 materials flammability data published by WSTF (ref. 7) demonstrate that the $1 \mathrm{~g}$ MOCs are not generally a strong function of pressure but instead vary primarily with oxygen concentration. This is somewhat surprising given that Test 1 is an upward flame spread test and the current results showed a square root dependence on pressure shown above for forced flow concurrent flame spread. Also, the partial gravity correlations for upward flame spread developed by Kleinhenz et al., showed a $\mathrm{P}^{2}$-g dependence (refs. 22 and 23). In spite of this data, the $1 \mathrm{~g}$ MOC is not a strong function of pressure and we examine this trend here.

We plot the flammability data from (ref. 7) in figure 10 along with the normoxic curve and lines of constant flame spread rate from the above flame spread correlations for both opposed flow and concurrent flow. Notice that the $1 \mathrm{~g}$ MOC data obtained from Test 1 results in nearly vertical lines for the different fuels: to the right of the line the materials are flammable, but to the left of the line they are not. There are a few exceptions to the near-vertical flammability lines, and those fuels appear to have halogen species in common (fuels indicated with an asterisk). Halogens are known to scavenge free radicals in the gas-phase, which inhibits the gas-phase reaction and thus the heat release from the flame. So these fuels have a stronger dependence on pressure, where at low pressure the increased diffusive mixing results in increased scavenging. The reduced heat release results in a higher oxygen limit at low pressure.

The lack of pressure dependence of the flammability data agrees better with the lines of constant flame spread rate for 


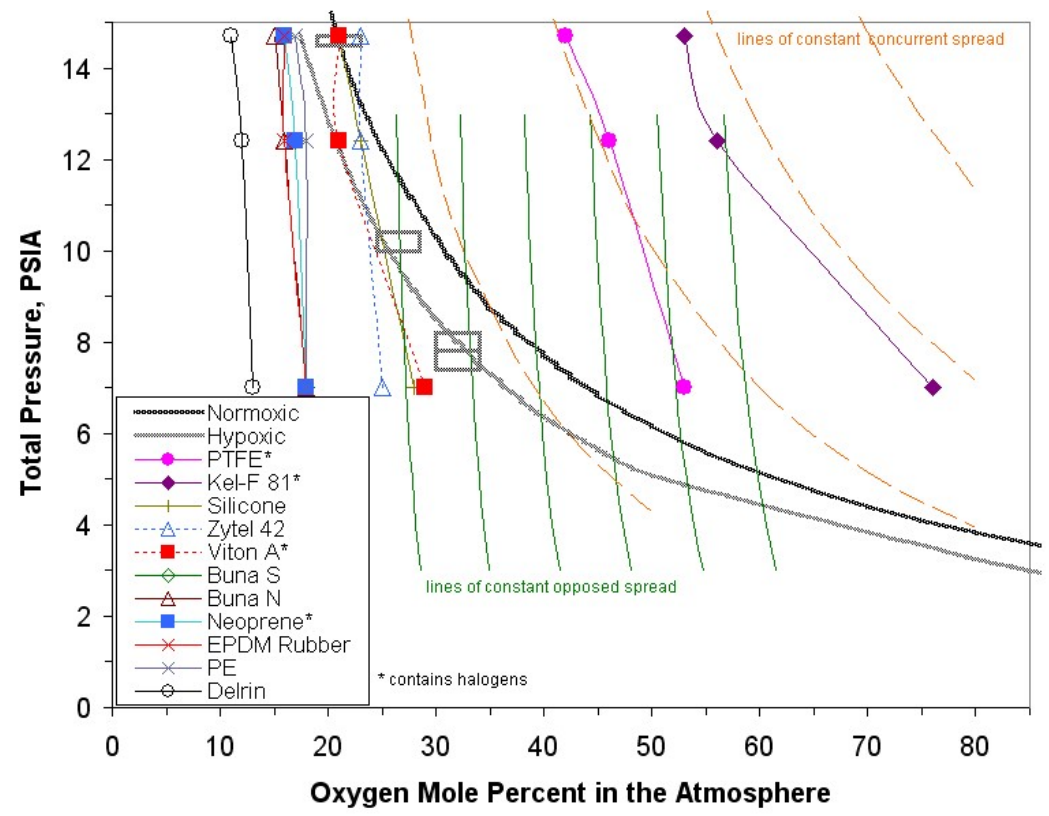

Figure 10.-MOC material flammability limits (ref. 7) compared to lines of constant spread rate from the opposed and concurrent flame spread correlations. The normoxic curve is shown as an indication of potential spacecraft atmospheres. The boxes shows the range of conditions expected in the CEV and lunar lander. The experimental data agree better with the opposed flow correlation, even though they were obtained in a concurrent configuration. The vertical lines correspond to critical heat flux for ignition boundaries and the near limit upward spreading flame is viable only for sufficient heat flux.

the opposed flow correlation rather than the concurrent flow correlation, as shown in figure 10. This is surprising as well, since the flammability data is in an upward flame spread configuration and one might expect the concurrent correlation trend to agree better.

We propose that the upward flammability limit (1g MOC) derived from Test 1 is essentially a limit dictated by the critical heat flux for ignition, where the heat flux from the flame is insufficient to sustain the burning. The similarity between the upward flammability limit and the lines of constant opposed flow flame spread rate can then be directly related. As was shown in (ref. 24), the limiting opposed flow flame spread velocity is directly related to the critical heat flux for ignition. Therefore, one of the lines of constant opposed flow flame spread rate will be the limiting spread rate, which is also the line of constant critical heat flux for ignition. This line would then correspond to the upward flammability limit of Test 1 . If this hypothesis is verified by further experiments and analysis, it could help to understand the flammability limits derived from Test 1 .

\section{Conclusions}

Microgravity tests of flammability and flame spread were performed in a low-speed flow tunnel mounted on a $5.18 \mathrm{sec}$ NASA drop vehicle. Three thin fuels were tested for flammability (Ultem 1000, 10 mil film, Nomex HT90-40, and Mylar
G). Kimwipes fuel supported a flame that spread rapidly enough that flame spread rates could be obtained in the short microgravity time. This was the first time that two of the fuels, Ultem 1000 and Mylar G), were tested in a microgravity environment. The $1 \mathrm{~g}$ ULOI and $1 \mathrm{~g}$ MOC flammability limits obtained from NASA Test 1 are compared to $0 \mathrm{~g}$ limits for the same fuel width. The $1 \mathrm{~g}$ ULOI and $1 \mathrm{~g}$ MOC are found to be greater than those in $0 \mathrm{~g}$, by up to $4 \%$ oxygen mole fraction, meaning that the fuels burned in $0 \mathrm{~g}$ at lower oxygen concentrations than they did using the Test 1 protocol. While test times in $0 \mathrm{~g}$ are limited to $5.18 \mathrm{sec}$, these test data provide a conservative estimate of the material's flammability in $0 \mathrm{~g}$.

The flame spread tests were used to develop correlations that capture the effects of flow velocity, oxygen concentration, and pressures on flame spread rate. For the case of opposed flow data, a previously determined correlation was found to be valid away from the quench limit. No correlation with these three variables for concurrent data existed, so our flame spread correlation is the first to combine the effects of oxygen, pressure, and forced flow velocity.

These correlations were used to determine the oxygen versus forced flow boundary where concurrent spread is faster than opposed flame spread. This boundary revealed that over virtually the entire range of spacecraft atmospheres and flow conditions, the opposed spread is faster in microgravity, especially for the normoxic case. The correlations were further used to compare with $1 \mathrm{~g} \mathrm{MOC}$ limit trends of materials as a 
function of pressure and oxygen. The lines of constant opposed flow agreed best with the $1 \mathrm{~g}$ MOC trends, which can be explained if the upward flammability limit derived from Test 1 is essentially a limit dictated by the critical heat flux for ignition, where the heat flux from the flame is insufficient to sustain the burning. Further evaluation of these and other materials is continuing to better understand the $0 \mathrm{~g}$ flammability of materials and its effect on the oxygen margin of safety.

\section{References}

1. Campbell, P.D., "Recommendations for Exploration spacecraft Internal Atmospheres: The Final Report of the NASA Exploration Atmospheres Working Group," JSC-63309, (January 2006).

2. Lewis, J.F, Barido, R.A, and Tuan, G. "Crew Exploration Vehicle Environmental Control and Life Support Fire Protection Approach," International Conference on Environmental Systems, SAE 2007-01-3255, July 2007.

3. "Flammability, Odor, Offgassing, and Compatibility Requirements and Test Procedures for Materials in Environments that Support Combustion," NASA STD 6001, Test 1, Upward Flame Propagation, (formerly NHB 8060.1C), February 9, 1998.

4. Hirsch, D.B, and Beeson, H.D., "Improved Test method to Determine Flammability of Aerospace Materials," Halon Options Technical Working Conference, April 2001.

5. Hirsch, D.B., and Beeson, H.D. "Test Method to Determine Flammability of Aerospace Materials," Journal of Testing and Evaluation, vol. 30, issue 2, (4 pages), March 2002.

6. Hirsch, D.B, Williams, J.H, Harper, S.A., Beeson, H., and Pedley, M.D.; "Oxygen Concentration Flammability Thresholds of Selected Aerospace Materials considered for the Constellation Program," Second IAASS Conference: Space Safety in a Global World, Chicago, IL, May 2007.

7. Hirsch, D.B, Williams, J., and Beeson, H.; "Pressure Effects on Oxygen Concentration Flammability Thresholds of Polymeric Materials for Aerospace Applications," Journal of Testing and Evaluation, vol. 36, issue 1, pp. 69-72. NASA Document ID 20070018178, 2008.

8. Hirsch, D.B., NASA-WSTF, personal communication.

9. Olson, S.L., Combustion Science and Technology, vol. 76 nos. 4-6, pp. 233-249, 1991.

10. Klimek, R. and Wright, T., Spotlight image analysis software, http://microgravity.grc.nasa.gov/spotlight/, 2005.

11. Sauers, D.G.; "The Effects of Forced Air Flow and Oxygen Concentration on Flammability, Smoke Density, and Pyrolytic Toxicity,” J. Fire Flammability, vol. 7, pp. 181-199, 1976.

12. Olson, S.L, and Miller, F.J. "Experimental Comparison of Opposed and Concurrent Flame Spread in a Forced Convective Microgravity Environment," submitted to the Proc. Comb. Inst 32, 2008.

13. Magee, R.S. and McAlevy III, R.F., J. Fire \& Flammability, vol. 2, pp. 271-297, 1971.
14. Olson, S.L., Ferkul, P.V., and T'ien, J.S., "Near-Limit Flame Spread Over a Thin Solid Fuel in Microgravity," 22nd Symposium (International) on Combustion," The Combustion Institute, pp. 1213-1222, 1988.

15. Olson, S.L., "The Effect of Microgravity on Flame Spread Over a Thin Fuel," NASA TM-100195, 1987.

16. Ferkul, P.F., "An Experimental Study of Opposed Flow Diffusion Flame Extinction Over a Thin Fuel in Microgravity," NASA CR-182185, Feb. 1989.

17. Bhattacharjee, S., Altenkirch, R.A., Sacksteder, K., J. Heat Transfer, 118, pp. 181-190, (1996).

18. Ferkul, P.V., "A Model of Concurrent Flow Flame Spread Over a Thin Solid Fuel," NASA CR-191111, 1993.

19. Grayson, G., Sacksteder, K.R., Ferkul, P.V., T'ien, J.S., Microgravity Science and Technology, vol. 11, no. 2, pp. 187-195, 1994.

20. Pettegrew, R.D., "An Experimental Study of Ignition Effects and Flame Growth over a Thin Solid Fuel in Low-Speed Concurrent Flow Using Drop-Tower Facilities," NASA CR-198537, Oct. 1996.

21. Di Blasi, C., Fire Mater. vol. 22, pp. 95-101, 1998.

22. Kleinhenz, J.E., "Flammability and Flame Spread of Nomex and Cellulose in Space Habitat Environments," Ph.D. Dissertation, CWRU, May 2006.

23. Feier, I.I., Kleinhenz, J., T'ien, J.S., Ferkul, P.V., and Sacksteder, K. "Pressure Modeling of Upward Flame Spread Rates in Partial Gravity," 43rd AIAA Aerospace Sciences Meeting and Exhibit, Reno, NV, Jan. 2005.

24. Olson, S.L., Miller, F.J., and Wichman, I.S., "Characterizing Fingering Flamelets Using the Logistic Model," Combustion Theory and Modelling, vol. 10, no.2, pp. 323-347, 2006.

\section{Nomenclature}

$\begin{array}{ll}1 \mathrm{~g} & \text { normal gravity } \\ 0 \mathrm{~g} & \text { microgravity } \\ \mathrm{CEV} & \text { Crew Exploration Vehicle } \\ \mathrm{CxP} & \text { Constellation Program } \\ \text { EVA } & \text { Extra Vehicular Activity } \\ \mathrm{ISS} & \text { International Space Station } \\ \text { LOI } & \text { limiting oxygen index (downward or opposed) } \\ \mathrm{M} \& P & \text { NASA Materials and Processes } \\ \mathrm{MOC} & \text { maximum oxygen concentration at extinction } \\ \text { NASA } & \text { National Aeronautics and Space Administration } \\ \text { PEI } & \text { polyetherimide } \\ \text { ULOI } & \text { upward limiting oxygen index (burning) } \\ \mathrm{WSTF}_{\Delta \mathrm{O}_{2} \%{ }_{0 \mathrm{~g}-1 \mathrm{~g}}} & \text { White Sands Test Facility } \\ & \text { the difference between the 0g mean flammabil- } \\ & \text { ity limit and the 1g mean flammability limit, } \\ & \text { see eq. (1). }\end{array}$




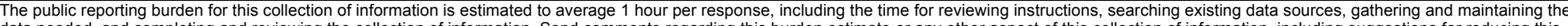

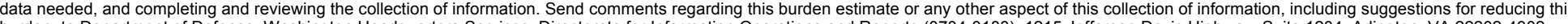

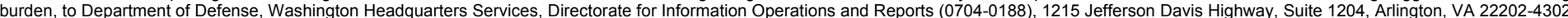

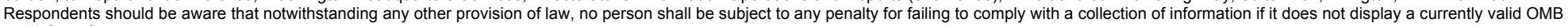
control number.

PLEASE DO NOT RETURN YOUR FORM TO THE ABOVE ADDRESS.

\section{REPORT DATE (DD-MM-YYYY) \\ 2. REPORT TYPE \\ 3. DATES COVERED (From - To)}

01-08-2008

\section{TITLE AND SUBTITLE}

Technical Memorandum

Microgravity Flame Spread in Exploration Atmospheres: Pressure, Oxygen, and Velocity

Effects on Opposed and Concurrent Flame Spread

5a. CONTRACT NUMBER

5b. GRANT NUMBER

5c. PROGRAM ELEMENT NUMBER

6. AUTHOR(S)

Olson, Sandra, L.; Ruff, Gary, A.; Miller, Fletcher, J.

\section{5d. PROJECT NUMBER}

5e. TASK NUMBER

5f. WORK UNIT NUMBER

WBS 344397.04.01.03

\section{PERFORMING ORGANIZATION NAME(S) AND ADDRESS(ES}

National Aeronautics and Space Administration

8. PERFORMING ORGANIZATION

REPORT NUMBER

John H. Glenn Research Center at Lewis Field

E-16527

Cleveland, Ohio 44135-3191

\section{SPONSORING/MONITORING AGENCY NAME(S) AND ADDRESS(ES)}

National Aeronautics and Space Administration

Washington, DC 20546-0001

10. SPONSORING/MONITORS
ACRONYM(S)
NASA
11. SPONSORING/MONITORING
REPORT NUMBER
NASA/TM-2008-215260; 2008-01-2005

\section{DISTRIBUTION/AVAILABILITY STATEMENT}

Unclassified-Unlimited

Subject Categories: 27, 54, 16 and 34

Available electronically at http://gltrs.grc.nasa.gov

This publication is available from the NASA Center for AeroSpace Information, 301-621-0390

\section{SUPPLEMENTARY NOTES}

\section{ABSTRACT}

Microgravity tests of flammability and flame spread were performed in a low-speed flow tunnel to simulate spacecraft ventilation flows. Three thin fuels were tested for flammability (Ultem 1000 (General Electric Company), 10 mil film, Nomex (Dupont) HT90-40, and Mylar $\mathrm{G}$ (Dupont) and one fuel for flame spread testing (Kimwipes (Kimberly-Clark Worldwide, Inc.). The 1g Upward Limiting Oxygen Index (ULOI) and $1 \mathrm{~g}$ Maximum Oxygen Concentration (MOC) are found to be greater than those in $0 \mathrm{~g}$, by up to $4 \%$ oxygen mole fraction, meaning that the fuels burned in $0 \mathrm{~g}$ at lower oxygen concentrations than they did using the NASA Standard 6001 Test 1 protocol. Flame spread tests with Kimwipes were used to develop correlations that capture the effects of flow velocity, oxygen concentration, and pressure on flame spread rate. These correlations were used to determine that over virtually the entire range of spacecraft atmospheres and flow conditions, the opposed spread is faster, especially for normoxic atmospheres. The correlations were also compared with $1 \mathrm{~g}$ MOC for various materials as a function of pressure and oxygen. The lines of constant opposed flow agreed best with the $1 \mathrm{~g}$ MOC trends, which indicates that Test 1 limits are essentially dictated by the critical heat flux for ignition. Further evaluation of these and other materials is continuing to better understand the $0 \mathrm{~g}$ flammability of materials and its effect on the oxygen margin of safety.

\section{SUBJECT TERMS}

Flame; Oxygen; Pressure; Microgravity

\begin{tabular}{|c|c|c|c|c|}
\hline \multicolumn{3}{|c|}{ 16. SECURITY CLASSIFICATION OF: } & \multirow{2}{*}{$\begin{array}{l}\text { 17. LIMITATION OF } \\
\text { ABSTRACT } \\
\text { UU }\end{array}$} & \multirow{2}{*}{$\begin{array}{l}\text { 18. NUMBER } \\
\text { OF } \\
\text { PAGES } \\
14\end{array}$} \\
\hline $\begin{array}{l}\text { a. REPORT } \\
\mathrm{U}\end{array}$ & $\begin{array}{l}\text { b. ABSTRACT } \\
U\end{array}$ & $\begin{array}{l}\text { c. THIS } \\
\text { PAGE } \\
\text { U }\end{array}$ & & \\
\hline
\end{tabular}

19a. NAME OF RESPONSIBLE PERSON
STI Help Desk (email:help@sti.nasa.gov)
19b. TELEPHONE NUMBER (include area code)
301-621-0390



